\title{
Physiopathology of Experimental Parkinsonism in the Monkey
}

\author{
LOUIS J. POIRIER, MICHEL FILION, LOUIS LAROCHELLE, AND JEAN-CLAUDE PÉCHADRE
}

SUMMARY: Postural or Parkinson-like tremor, which results from the impairment of mechanisms which are predominantly lateralized in the brain, is most likely related to the combined impairment of the dopaminergic nigrostriatal pathway and the corresponding rubroolivo-cerebello-rubral loop (without excluding the possibility that other nervous mechanisms interconnected with these structures may represent an alternative disturbance). The integrity of the internal division of the pallidum and the ventrolateral area of the thalamus and their efferent fibers as well as the motor cortex and certain of its cortico-subcorticospinal pathways (Figures 1 and 2) is apparently an essential feature for the elaboration of the rhythmic bursts associated with the appearance of postural tremor. The integrity of the spinal sensory roots and the rubro-tegmentospinal tract is not a prerequisite for the expression of postural tremor, a condition which seems essential for the production of rigidity. The latter facts suggest that the disturbances which subserve these two types of motor impairment, often concomitantly present in Parkinsonism, partially involve the impairment of different mechanisms although the loss of the DA fibers originating in the substantia nigra and ending in the neostriatum (Figure 1) appears to represent a disturbance common to both types of disorders.

Bradykinesia which may be associated with an impairment of catecholamine metabolism (and more especially the neostriatal DA mechanisms) on both sides of the brain may also result from

(Please turn to page 261)
RÉSUMÉ: Le tremblement postural ou parkinsonien qui implique un malfonctionnement de mécanismes nerveux qui de façon prédominante sont latéralisés au niveau cérébral met plus particulièrement en cause une atteinte de la voie nigrostriée dopaminergique et de la boucle rubro-olivo-cérébello-rubrique correspondante (sans exclure la possibilité que d'autres mécanismes nerveux étroitement reliés à ces structures puissent être impliqués) (Figures 1 et 2). L'intégrité de la division médiane du pallidum, de la partie ventrolatérale $d u$ thalamus y compris ses efférences et le cortex moteur et ses efférences corticosubcorticospinales est, selon toute évidence, une condition essentielle à l'élaboration des bouffées rythmiques responsables de la manifestation du tremblement postural. Par ailleurs l'intégrité des racines sensorielles spinales et de la voie rubro-tegmentospinale n'est pas un facteur déterminant dans la manifestation du tremblement postural alors que leur intégrité est apparemment essentielle à l'apparition de la rigidité. Ces faits suggèrent que les perturbations qui sous-tendent ces deux types d'anomalies motrices (tremblement et rigidité) fréquemment associées dans le parkinsonisme impliquent en partie des mécanismes différents alors que l'inactivation de la voie nigrostriée dopaminergique semble représenter un trouble commun à ces deux perturbations de l'activité motrice.

La bradykinésie souvent associée à un trouble du métabolisme catécholaminergique (et plus particulièrement les mécanismes dopaminergiques néostriat(Please turn to page 262)
Over approximately the last three decades the characteristic signs of Parkinsonism have been experimentally reproduced by lesions or drugs or a combination of both procedures in monkeys (Poirier and Sourkes, 1972; Poirier et al., 1975).

\section{POSTURAL OR RESTING TREMOR}

Postural or resting tremor has been observed as a transient phenomenon following tegmental lesions of the pons and midbrain by Mettler and Whittier (1947); Ward et al. (1948); Peterson et al. (1949) and Carpenter (1956). Poirier (1960) and Poirier et al. (1966, 1969b, 1972a) have described sustained postural tremor that involved the contralteral limbs following unilateral lesions of the midbrain ventromedial tegmental area. The tremor resulting from such lesions was most often associated with hypotonicity and/or hypokinesia of the corresponding limbs (Poirier, 1960; Poirier et al., $1969 \mathrm{~b})$. These findings have led to different conclusions. Thus Peterson et al. (1949) suggested that the tremor resulting from tegmental lesions could be a consequence of the interruption of "supressor relays descending from the basal ganglia". In the light of more recent data concerning the distribution of the efferent nervous pathways from the basal ganglia (Nauta and Mehler, 1966; Kuo and Carpenter, 1973), however, the midbrain tegmentum does not appear to receive important descending nervous fascicles from the striopallidal structures. Taking account of the presence of abundant ascending cerebellofugal fibers and of the red nucleus at the level of the midbrain tegmentum Carrea and Mettler (1947) proposed that the in-
From the Laboratoires de Neurobiologie, Faculte de Medicine, Universite Laval, Quebec, Que., Canada.

Reprint requests to Dr. Louis J. Poirier, Laboratoires de Neurobiologie, Université Laval, Quebec, Canada G1K 7P4. 


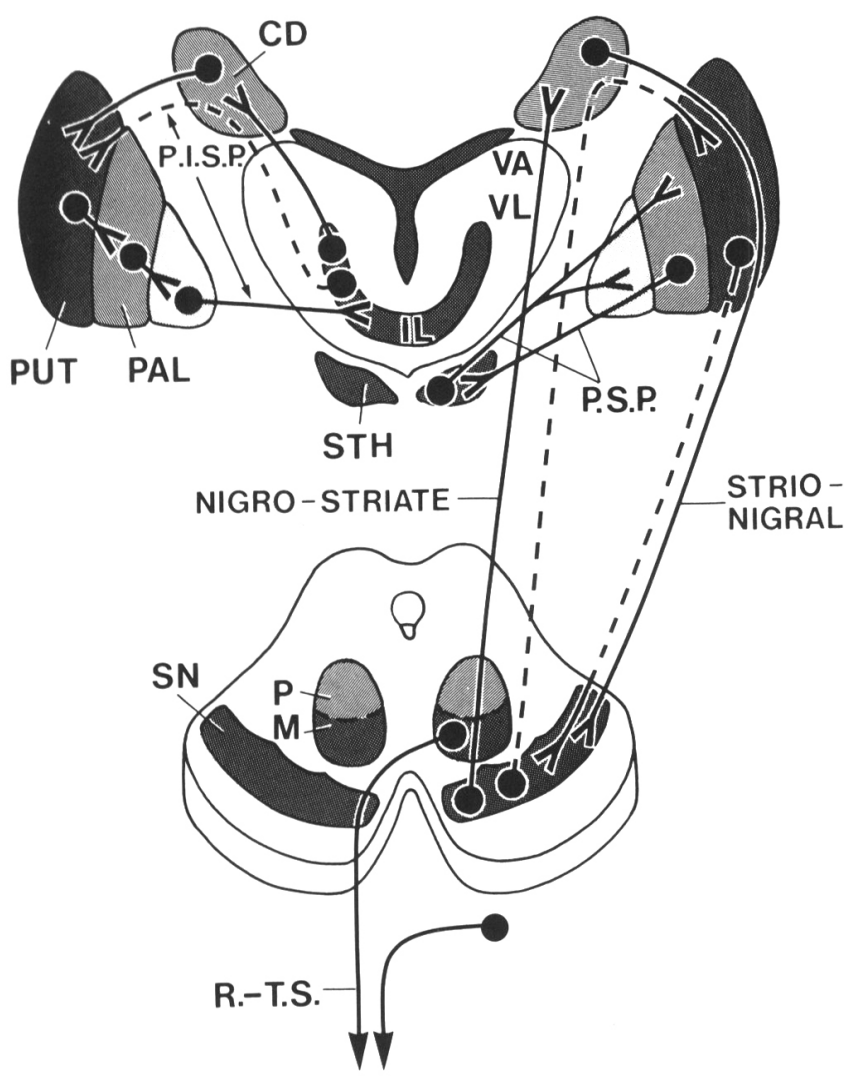

Figure 1 (above)-Schematic drawing of the rubrotegmentospinal tract (R.-TS.) and of intrinsic connections of striopallidal (extrapyramidal) system. CD, caudate nucleus; IL, intralaminar nuclei; M.P., magnocellular and parvocellular division of red nucleus, resp.; PAL, pallidum; P.I.S.P., pallido-intralamino-strio-pallidal loop; PSP, pallidosubthalamo-pallidal loop; SN, substantia nigra; STH, subthalamic nucleus; VA, VL ventral anterior and ventral lateral thalamic nuclei.

Figure 2 (right)-Schematic drawing to illustrate the outflow of the striopallidal system and corticofugal and cerebellofugal fibers related to the striopallidal system. The rubro-olivocerebello-rubral loop is also shown. C.S., corticospinal

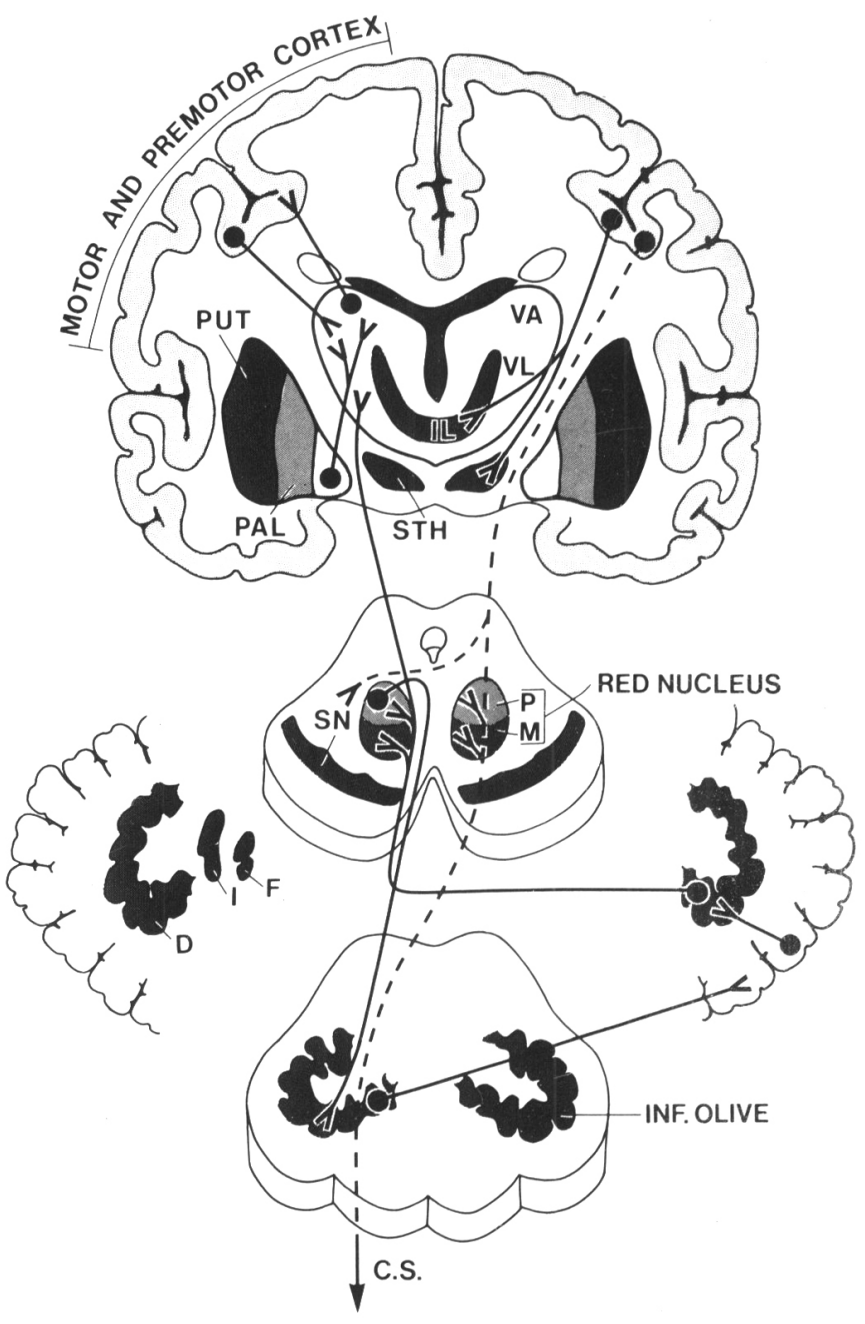

pathways; D.I.F., cerebellar dentate, interpose and fastigial nuclei; IL, intralaminar nuclei; M.P., magnocellular and parvocellular division of the red nucleus, respectively; PAL, pallidum; PUT, putamen; SN, substantia nigra; STH, subthalamic nucleus; VA, VL, ventral anterior and ventral lateral thalamic nuclei. terruption of the ventral component of the brachium conjunctivum is an important factor in the production of "simple" tremor. Carpenter (1961) suggested a somewhat different explanation considering that postural tremor results from damage to the ascending cerebellofugal fibers caudal to the level of the red nucleus. Poirier (1960) observed that upper brain stem tegmental lesions resulting in postural tremor were associated with a marked cell loss in the homolateral substantia nigra. Therefore it was suggested that this type of tremor may imply the combined involvement of nigral ascend- ing efferents and the corresponding rubrospinal tract (Figure 1) (Poirier, 1960). The cell loss in the substantia nigra associated with such lesions in animals is closely related to the well-known neuropathological changes described in the substantia nigra of patients with Parkinsonism (Trétiakoff, 1919; Hassler, 1938; Escourolle et al., 1971).

Parkinson-like signs including postural tremor have been observed following the chronic administration of reserpine (Bein, 1953) and phenothiazine (Delay et al., 1950; Bernheimer and Hornykiewicz, 1965) and butyrophenone deriva- tives (Divry et al., 1960) to nonParkinsonian patients. In the monkey harmaline, a short-acting monoamine oxidase inhibitor which causes peculiar metabolic effects (Singh et al., 1967), either increases the already present postural tremor, or else, may induce tremor in nontremoring monkeys with lesions that may spare the nigrostriatal pathway (Poirier et al., 1966, 1969b).

The disclosure of distrubances of monoaminergic metabolism especially at the level of the striatum in the brains of Parkinsonian patients (Ehringer and Hornykiewicz, 1960; Bernheimer et al., 1961, 1973; Hor- 
nykiewicz, 1966) and of monkeys with lesions-induced Parkinsonian signs (Poirier et al., 1966, 1969b, 1972a; Goldstein et al., 1969b) has permitted the establishment of the relationship between these metabolic disturbances and the appearance of Parkinsonian signs. Such a relationship has been greatly facilitated by the identification of the monoaminergic neurons and the distribution of their efferent fibers with the help of the histofluorescence method (Dahlstrom and Fuxe, 1964; Anden et al., 1965) and the combined use of biochemical and histopathological approaches (Poirier and Sourkes, 1965, 1972; Sourkes and Poirier, 1966; Goldstein et al., $1966,1969 a)$. On the one hand, these various data have determined the importance of the histopathological changes at the level of the substantia nigra and the associated dopamine decrease in the neostriatum (caudate nucleus and putamen) in the production of the most characteristic signs of Parkinsonism. On the other hand these findings have also contributed in elucidating drug-induced Parkinsonism as these drugs have been shown to interfere with brain monoamine metabolism. Thus the interruption of the nigrostriatal pathway leads to a cell loss (retrograde degeneration) in the corresponding substantia nigra and an associated decrease of dopamine (DA) in the ipsilateral neostriatum (Poirier and Sourkes, 1965; Poirier et al., 1966), the latter effect most likely resulting from the loss of important enzymes involved in monoamine metabolism, namely, tyrosine hydroxylase (Goldstein et al., 1966; Poirier et al., 1969c) and DOPA (5-HTP) decarboxylase (Anden et al., 1966; Goldstein et al., 1969a; Lancaster et al., 1970). Similar enzymic defects have also been disclosed in the brains from Parkinsonian patients (Lloyd and Hornykiewicz, 1970).

In other studies it was observed that ventromedial tegmental lesions that interrupted the nigrostriatal pathway ending in the striatum without extensively damaging other structures did not result in tremor even when harmaline was injected to the animals. In contradistinction monkeys with more dorsally located lesions of the tegmentum that spared the nigrostriatal pathways displayed tremor of the contralateral limbs in response to harmaline (Poirier et al., 1969b). The latter findings suggested that harmaline may in some way duplicate the effect of interrupting the dopaminergic mechanisms by causing a transient inactivation of the latter mechanisms. In addition, the above observations suggest that the production of postural tremor not only involves the impairment of the striatal dopaminergic mechanism but also the disruption of other nervous mechanisms. In the light of these data, lesions were placed in different sites of the lower brain stem in order to interrupt the rubro-olivocerebello-rubral loop at different sites (Larochelle et al., 1970). Such lesions which per se did not cause tremor resulted in tremor when harmaline was injected. Thus a lesion destroying either the rubro-olivary component of the central tegmental tract, the principal inferior olive, olivo-cerebellar fibers before their crossing or cerebellofugal fibers after their crossing in the superior cerebellar peduncle resulted in tremor of the contralateral limbs after the administration of harmaline. Harmaline was also associated with tremor of the ipsilateral limbs in monkeys with lesions that damaged the olivo-cerebellar fibers after their crossing, the lateral (dentate) cerebellar nucleus or the cerebellofugal fibers before their crossing in the superior cerebellar peduncle. From these findings it was concluded that this loop (Figure 2) which includes the parvocellular division of the red nucleus, the corresponding rubroolivary fibers, the corresponding part of the inferior olive and its efferent fibers, the cerebellar cortex and the lateral cerebellar nucleus and its efferent fibers represents an important mechanism in the control of motor activity.

In the light of these findings alpha-methyl-p-tyrosine (AMT), a known tyrosine hydroxylase inhibitor (Spector et al., 1965; Uden- friend et al., 1965), which leads to a gradual decreased concentration of dopamine (DA) and noradrenaline (NA), was tested in lesioned monkeys. The injection of AMT $(150 \mathrm{mg} / \mathrm{kg}$, i.p.) to monkeys with lesions of the rubro-olivo-cerebellorubral loop caused postural tremor which took place 5-7 $\mathrm{h}$ after the injection of the drug. Under such conditions the administration of L-DOPA (appprox. $30 \mathrm{mg} / \mathrm{kg}$, i.p.) abolished the AMT-induced tremor within 10-15 min. for a period of approximately $45 \mathrm{~min}$. (Bédard et al., 1970; Larochelle et al., 1971). This effect is most likely related to the conversion of dopa to dopamine within the terminals of the nigrostriatal pathways which are spared in animals with such lesions. Therefore these results point to the importance of the inactivation of the neostriatal DA mechanisms in the production of postural tremor. This is further supported by the fact that reserpine which depletes monoamines stores, and thioproperazine, which, like other phenothiazine derivatives, blocks the dopamine receptors, also induce tremor in monkeys with lesions of the rubro-olivo-cerebellorubral loop (Larochelle et al., 1971). The Parkinson-like syndrome (including postural tremor) observed following the chronic administration of reserpine, and phenothiazine and butyrophenone derivatives (see references above) to non-Parkinsonian patients further substantiates the possibility that the involvement of brain monoaminergic mechanisms represents an important factor in the appearance of tremor and other signs of Parkinsonism. These drugs which interfere with the metabolism of monoamines duplicate in some way or another the effects of lesions encountered in Parkinsonism.

Anticholinergic drugs, in spite of annoying side-effects, have been shown to counteract Parkinsonian signs. In view of the fact that the neostriatum (caudate nucleus and putamen) is rich in acetylcholine and the corresponding metabolic enzymes, cholinesterase and choline acetylase, it is conceivable that the cholinergic mechanisms of the neostriatum deprived of the influence of 
the dopaminergic endings (as a consequence of the interruption of the nigrostriatal pathway or the pharmacological inactivation of the DA mechanisms) play an important role in the production of the abnormal rhythmic bursts associated with postural tremor (Figure 2). In this respect it is worth mentioning that postural tremor induced in lesioned monkeys by AMT, reserpine and thioproperazine is abolished by benztropine (Larochelle et al., 1971). It is also pertinent to mention that the internal division of the pallidum which is involved in the production of tremor (cf postea) is recipient of important cholinesterasic (Olivier et al., 1970) and gabaminergic (Kim et al., 1971) nervous fascicles originating in the neostriatum.

The results of stereotaxic surgery point to the fact that the globus pallidus and the ventrolateral area of the thalamus whose destruction may alleviate Parkinsonian tremor and rigidity (Myers, 1942; Guiot and Brion, 1953; Cooper and Bravo, 1958; Hassler and Riechert, 1958) are actively involved in the elaboration of the rhythmic bursts associated with resting tremor. The evidence that tremor is not abolished by deafferentation of the limbs in Parkinsonian patients (Pollock and Davis, 1930) and in lesioned monkeys (Ohyé et al., 1970) supports the idea that the abnormal rhythmic bursts are centrally built up. In this respect the motor and premotor cortices together with the ventrolateral thalamus and the corresponding pallidum apparently play an important role in the elaboration of the abnormal rhythmic activity associated with postural tremor (Figure 2). As a matter of fact postural tremor may be abolished by removal of the motor cortex in Parkinsonian patients (Klemme, 1940; Bucy and Case, 1949) and in lesioned monkeys (Poirier et al., 1969b). Therefore the nervous circuitry represented by the pallidothalamic fibers to the $\mathrm{VL}$, corresponding thalamocortical fibers and corticofugal fibers from the motor areas of the cortex plays an important role in the elaboration and in downward transmission of im- pulses responsible for the production of postural tremor (Figure 2).

The interruption of the direct corticospinal fibers at peduncular (Poirier et al., 1966) or spinal cord level (Ohyé et al., 1970) however, does not prevent the appearance of postural tremor in monkeys (as also reported in hemiplegic patients). These facts coupled with the observation that the destruction of the motor cortex (associated with a partial degeneration of the pyramid) abolishes tremor, suggest that the indirect cortico-subcortico-spinal system (from the motor cortex) is more directly involved than the direct corticospinal system in the transmission of the nervous impulses related to the production of postural tremor.

In the light of the data summarized above it appears that Parkinson-like tremor involves the combined impairment of the striopallidal system and the rubro-olivocerebello-rubral loop (or nervous connections directly related to this loop (Figures 1 and 2). The most characteristic disturbance within the striopallidal system implies the dopaminergic mechanism which morphologically corresponds to the nigrostriatal pathway. The latter pathway includes the neurons of the substantia nigra and nucleus parabrachialis pigmentosus and their endings in the homolateral caudate nucleus and putamen which in turn give rise to strionigral fibers (Voneida, 1960; Szabo, 1962). The latter group of fibers (strionigral), particularly rich in acetylcholinesterase (Olivier et al., 1970), may represent a feedback mechanism by which the neostriatum controls its own needs in DA. Moreover, the strionigral pathway is involved in the elaboration of GABA in the corresponding nigra (Kim et al., 1971; McGeer et al., 1973). Therefore different putative neurotransmitters are possibly responsible for the control of the nervous activity at the level of the substantia nigra.

The neostriatum also gives rise to other acetylcholinesterasic (Olivier et al., 1970) and gabaminergic (Kim et al., 1971; McGeer et al., 1973) fibers ending in the globus pallidus.
Therefore an impairment of the DA mechanism of the neostriatum in turn may result in a disturbance of the nervous activity within the pallidum and correspondingly in the ventrolateral area of the homolateral thalamus and motor cortex. As mentioned earlier destruction or removal of these structures may alleviate postural tremor suggesting that they play an important role in the elaboration of the rhythmic activity associated with this type of tremor. In so far as the pallidum is concerned Filion and others (1974) have disclosed abnormal rhythmic activities in the internal division of this structure in a monkey that displayed akinesia and postural tremor and rigidity (associated with the cogwheel phenomenon) of the four limbs following bilateral upper brain stem lesions (Larochelle et al., 1974). A similar syndrome had been described earlier in two monkeys (Poirier, 1960). Using a technique for recording extracellular unit activity in unanesthetized animals pallidal neurons from both sides were recorded in the above-mentioned animals. All neurons displayed a high rate of discharge up to complete silence followed by a gradual return to pre-injection rates and patterns of discharge. These changes were coincident with the decrease and recovery of tremor, rigidity and akinesia (Filion et al., 1974). These data obtained in a monkey suggest that the bilateral interruption of the nigrostriatal DA pathways could be responsible for the abnormal nervous activity at the level of the striopallidum. This defect of nervous activity, however, is blocked when a DA agonist is used to counteract the signs of Parkinsonism.

As mentioned above postural tremor involves not only a disturbance within the striopallidal system (more especially the DA mechanism) but also an impairment of the corresponding rubro-olivo-cerebello-rubral loop. A disturbance of the latter mechanism most likely causes a peculiar imbalance within the cerebellum or, possibly, a loss of influence normally originating in this structure. This in turn, results in a disturbance of the output from the 
deep cerebellar nuclei. In view of the fact that drugs interfering with DA metabolism induce postural tremor in monkeys with lesion of the dentate nucleus (Larochelle et al., 1970) but not in monkeys with lesion of the medial (fastigial) and interpose nuclei (Poirier et al., 1974) it is conceivable that the main disturbance of the cerebellar outflow involved in the production of postural tremor may be identified with the efferent fibers of the dentate nucleus which predominantly project to the midbrain tegmentum and the thalamus. A modification or a loss of cerebellar influence to the ventrolateral thalamus may represent an important factor in the production of postural tremor. If this were the case, the expression of sustained postural tremor may well involve the loss or disturbance of a dual influence normally reaching the ventrolateral thalamus and originating in the cerebellar dentate nucleus and the internal division of the corresponding globus pallidus, respectively (Figures 1 and 2). Therefore it is not surprising that this area of the thalamus which is also interconnected with the motor cortex represents the most important target to destroy in order to alleviate postural tremor and rigidity in Parkinsonian patients.

\section{RIGIDITY}

In this paper rigidity characterized by increased muscle tone (as determined by passive movements of segments of the limbs) will be mainly discussed in relation to the so-called extrapyramidal disorders. The most common type of hypertonicity usually associated with the cog-wheel phenomenon is encountered in Parkinsonism as a consequence of disease or chronic treatment with certain neuroleptic drugs. According to Hoffman (1934) and Wiesendanger (1972) rigidity could result from an exaggeration of the tonic stretch reflexes as a consequence of a disturbance between the different supraspinal nervous impulses reaching the motor neurons. Rigidity as encountered in Parkinsonian patients is associated with histopathological changes involving different known monoaminergic structures and other structures (Trétiakoff, 1919; Hassler, 1938; Escourolle et al., 1971). It has been described as a more isolated phenomenon in association with strionigral degeneration (Adams et al., 1964; Rajput et al., 1972) a disease more specifically characterized by symmetrical degeneration of both putamina (Adams, 1968) and secondary atrophy of the globus pallidus, the latter defect being considered a consequence of the degeneration of the striatofugal fibers (Escourolle et al,, 1971). Attempts to produce rigidity by lesions, generally speaking, have not been successful and the hypertonicity reported following extensive brain stem damage is considered to be more closely related to spasticity than to Parkinson-like rigidity. Experimental ventromedial tegmental lesions in the monkey resulting in postural tremor are most often associated with hypotonicity in the corresponding limbs (Poirier, 1960; Poirier et al., 1969b, 1972a), a feature also reported in patients with Parkinsonism following traumatic lesions of the midbrain ventromedial tegmental area (Kremer et al., 1947). Hypertonicity associated with tremor of the limbs has been observed in two monkeys following bilateral lesions at the level of the rostral midbrain and caudal hypothalamus (Poirier, 1960). In more recent studies (Laorchelle et al., 1974; Péchadre et al., unpublished data) rigidity associated with the cogwheel phenomenon was produced in two monkeys. In both animals the lesions bilaterally destroyed important monoaminergic pathways (including the DA nigrostriatal pathways) at the base of the midbrain. They also involved cerebellothalamic and rubro-olivary fibers as well as the parvocellular division of the red nucleus on both sides in one monkey and on the right side in the other monkey. In the latter animal rigidity and postural tremor were. present only in the left limbs. Moreover, the magno-cellular division of the red nucleus and corresponding rubro-spinal and tegmentospinal pathways were spared in these two monkeys (Péchadre et al., unpublished data). In view of the fact that damage to the latter structures is associated with hypotonia of the limbs (Poirier, 1960; Poirier et al., 1966, 1969b) it appears reasonable to assume that the integrity of the magnocellular division of the red nuclei and of the rubro-tegmentospinal tracts is a prerequisite for the production of this type of rigidity. In the light of these data the involvement of monoaminergic pathways (especially the DA nigrostriatal pathways) and of the parvocellular division of red nucleus and/or the cerebellothalamic fibers apparently represent important factors in the production of rigidity. The impairment of the monoaminergic mechanisms (especially those of the neostriatum) in the production of rigidity is supported by the observation that severe monoaminergic disturbances have been disclosed in the brains of Parkinsonian patients (Hornykiewicz, 1966). This is further substantiated by pharmacological studies in man and animals. Akinesia, tremor and rigidity have often been described in nonParkinsonian patients following the chronic administration of drugs known to interfere with monoamine metabolism such as reserpine or phenothiazine and butyrophenone derivatives. The fact that L-DOPA may suppress reserpine-induced rigidity in these patients (Degkwitz et al., 1960) in whom the nigrostriatal DA mechanisms are presumably intact supports the idea that a brain catecholamine decrease or inactivation represents an important contributory factor in the genesis of rigidity. The administration of a single or a few large doses of reserpine or phenothiazine and butyrophenone derivatives most often do not result in rigidity (Bédard, 1971) despite the associated monoaminergic disturbances. The production of rigidity therefore appears to involve the long-term metabolic effects of these drugs which may interfere with various centers of the CNS in addition to their more specific effects on monoaminergic mechanisms. The possibility that a catecholaminergic defect (especially at the level of the striatum) represent an important fac- 
tor in rigidity is further substantiated by the observation that rigidity is transiently and completely alleviated by the administration of apomorphine in animals with tegmental lesions interrupting bilaterally the nigrostriatal pathways (Péchadre et al., unpublished data). As mentioned above the latter effect which is not duplicated by L-DOPA is associated with characteristic changes of the nervous activity at the level of the internal division of the globus pallidus as shown by recording from single units (Filion et al., 1974). Apomorphine which markedly decreases the activity of the neurons of the pallidum up to complete silence in monkeys with bilateral interruption of the nigrostriatal pathways, to some extent, duplicates the effects of surgical pallidectomy (Cooper, 1969) in Parkinsonian patients. The production of rigidity most likely implies an impairment of the rubroolivary tract and/or corresponding cerebello-thalamic fibers in addition to the monoaminergic defect. These data coupled with the evidence that rigidity may be either present or absent in Parkinsonian patients and moreover may be selectively reduced by rhizotomy (Pollock and Davis, 1930) or by thalamic surgery (Cooper, 1969) suggest that the CNS disturbances associated with rigidity are at least partially different than those responsible for the production of either akinesia or tremor. The integrity of the rubro-tegmento-spinal (Figure 1) system whose impairment apparently results in hypotonia (Poirier, 1960; Poirier et al., 1972a) and does not prevent the appearance of tremor (Poirier et al., 1969b) may represent an important feature in the production of rigidity.

\section{BRADYKINESIA AND AKINESIA}

In man bradykinesia and akinesia are more frequently associated with extrapyramidal disorders and more especially Parkinson's disease and Parkinsonism. The associated histopathological changes involve different areas of the brain stem and basal ganglia as a result of vascular, infectious, anoxic, metabolic and other disturbances. In this study it appears pertinent to take account of certain data observed in the brains of patients in whom akinesia represented an important feature.

In the light of most common histopathological changes found at the level of the substantia nigra, Trétiakoff (1919), Hassler (1938), Benda and Cobb (1942), and Escourolle et al. (1971) considered the reduction of the number of neurons as well as the cytoplasmic inclusions of the Lewy type and neurofibrillary degeneration as the most characteristic changes related to the production of Parkinsonism. These lesions in the substantia nigra are usually associated with more or less severe and diffuse damage in other structures of the brain stem and basal ganglia.

Severe akinesia in the absence of other Parkinsonian signs has been reported following complete and diffuse degeneration more or less restricted to the pallida (Contamin et al., 1971; Escourolle et al., 1971). As mentioned earlier neurochemical studies have revealed that brain monoamines and especially DA are in abnormally low concentrations, especially at the level of the neostriatum, in the brains of patients who had shown a Parkinsonian syndrome (Ehringer and Hornykiewicz, 1960; Hornykiewicz, 1963; Bernheimer et al., 1963, 1973). The suspected correlation between the histopathological changes in the substantia nigra and the associated decreased monamine concentration in the neostriatum was established in monkeys with lesion-induced Parkinsonism. The interruption of the nigrostriatal pathway leads to a retrograde degeneration of the corresponding substantia nigra whose severity is directly related to the importance of the DA depletion in the homolateral caudate nucleus and putamen (Poirier et al., 1966, 1969b).

Drug-induced Parkinsonism including more or less severe akinesia has been repeatedly reported in psychiatric patients chronically treated with neuroleptic drugs such as reserpine (Bein, 1953) and phenothiazine (Delay et al., 1956) and butyrophenone derivatives (Divry et al., 1960). All these drugs interfere with monoamine meta- bolism and, in some way, they more or less duplicate the effects of the lesions encountered in Parkinsonism. Bradykinesia without rigidity and tremor have been produced in non-lesioned animals by the injection of single dose of the above-mentioned drugs. Moreover bradykinesia induced by reserpine may be transiently counteracted by L-DOPA (Larochelle et al., 1971). Akinesia whose severity is dosedependent may also be produced in non-lesioned monkeys by the administration of alpha-methyltyrosine (AMT), a tyrosine hydroxylase inhibitor (Spector et al., 1965). This drug, however, does not prevent the conversion of L-DOPA to dopamine. Therefore the administration of L-DOPA completely and transiently reverses the AMTinduced akinesia provided that the nigrostriatal pathways are intact (Bédard et al., 1970; Larochelle et al., 1971). These results point to the relationship between the loss of monoamines and, more especially, DA within the nervous tissue and the production of bradykinesia and akinesia. As the concentration of DA in the nervous tissue is comparatively higher in the neostriatal tissue (amounting to approximately $80 \%$ of the DA content of the whole brain according to Hornykiewicz, 1971) than in other brain areas it is imaginable that the neostriatal DA plays a major role in the type of psychomotor activity associated with the performance of purposeful and spontaneous movements. More or less severe akinesia with or without catatonia or catalepsy may result from bilateral lesions placed at the level of the base of the rostral midbrain and/or caudal hypothalamus in different species (Ranson and Ingram, 1932; Ranson, 1939; Harrison, 1940; Poirier, 1960). These lesions more particularly interrupt ascending monoaminergic pathways ending in the neostriatum, the telencephalon and other structures of the upper brain stem (Heller et al., 1962; Poirier et al., 1967a, 1967b, 1969a; Bédard et al., 1969; Parent et al., 1969) and, in some way, they reproduce the monoaminergic inactivation 
achieved by the administration of such drugs as reserpine, AMT or phenothiazine and butyrophenone derivatives. A more careful study of the lesions located in these brain areas and of the associated behavioral effects, however, disclosed that certain lesions at caudal hypothalamic level may result in a slight decrease of spontaneous locomotor activity despite the fact that the DA pathways ending in the neostriatum are bilaterally and extensively involved. This is in contrast to the fact that bilateral lesions at the level of the rostral midbrain cause a severe akinesia which gradually develops postoperatively (Poirier, 1960). The latter findings raise the question whether a more complete interruption of the monoaminergic pathways is achieved by lesions at the level of the rostral midbrain than at the level of the caudal hypothalamus. In this respect it is worth mentioning that the bilateral destruction of the pallidofugal pathways at the level of Forel's $\mathbf{H}$ fields results only in bradykinesia which may be overcome by the animal (Péchadre et al., unpublished data). Under such conditions this procedure deprives areas receiving fibers from the striopallidal system not only of the influence of dopamine but also of other putative neurotransmitters such as GABA and acetylcholine. Therefore it appears that akinesia involves a more complete interruption of the monoaminergic pathways than the sole interruption of the dopaminergic pathways or even the almost complete exclusion of the influence of the striopallidal systems on other areas of the brain. Further work is needed to establish the relative importance of the loss of the DA nervous mechanisms over against other catecholaminergic pathways in the production of akinesia. Other catecholaminergic pathways possibly involved in the control of locomotor activity include ascending pathways ending in various structures of the midbrain, diencephalon and cortex.

The rapid effect of L-DOPA in counteracting akinesia induced by AMT or reserpine in the presence of intact nigrostriatal DA mechanisms must be judged alongside the fact that tremor is often exaggerated by L-DOPA in patients (Rondot and Ribadeau-Dumas, 1972) and moreover the antitremoregenic effect of L-DOPA takes place after a prolonged period of L-DOPA treatment in Parkinsonian patients. Therefore the beneficial effects of L-DOPA on bradykinesia and akinesia in patients with a loss of $\mathrm{DA}$ neostriatal mechanisms could imply ill-defined metabolic effects resulting from the chronic administration of L-DOPA. In contradistinction to the latter results, severe akinesia induced by bilateral ventromedial tegmental lesions at upper brain stem level (Poirier, 1960) may be transiently overcome by the administration of apomorphine (Larochelle et al., 1974), a dopamine agonist thought to produce its effect by stimulating the DA receptors (Ernst, 1967). Bradykinesia associated with the bilateral interruption of the pallidofugal fibers which represent the main outflow of the strio-pallidum system, however, is not reversed by apomorphine (Péchadre et al., unpublished data). On the one hand, the latter findings suggest that the integrity of the internal division of the pallidum (from which arise the pallidofugal fibers) (Figure 2) is essential for the beneficial effect of dopamine agonists on akinesia as well as on tremor and rigidity (cf antea). On the other hand these findings also suggest that dopamine agonists such as apomorphine exert their anti-Parkinsonian effects predominantly through the neostriatum. In this respect Filion et al. (1974) have observed that the abnormal activity of single neurons in the internal division of the pallidum associated with bilateral upper brain stem tegmental lesions is significantly decreased up to a complete arrest when apomorphine is peripherally administered (cf antea). Under such conditions the gradual decrease of abnormal nervous activity and its return to pre-injection patterns coincide with the disappearance and reappearance of akinesia, rigidity and tremor (Filion et al., 1974). These results suggest that DA agonists, such as apomorphine, which decrease the activity of the neurons of the internal pallidum to almost complete silence in the Parkinsonian monkey, produce effects that are similar to those associated with pallidectomy in Parkinsonian patients (Cooper, 1969).

\section{DISCUSSION}

Olivier (Montreal) inquired whether the effects of bilateral pallidal lesions in monkeys had been investigated, since the lesion in one of Poirier's monkeys extended forward to the level of the $4 \mathrm{H}$ field where it might involve pallidothalamic fibers. He wondered whether changes in the clinical picture as well as in single unit activity in globus pallidus might be the result of bilateral deprivation of pallidothalamic impulses. Poirier stated that he had attempted to produce bilateral pallidal lesions, but that in most cases there was also involvement of surrounding structures such as the internal capsule, making it difficult to determine whether the resulting akinesia was a specific effect of the pallidal lesion. He felt that the lesion at the level of the $4 \mathrm{H}$ fields did produce a Parkinsonian syndrome by interrupting pallidopetal fibers. Olivier wondered whether the apparent marked decrease in aggressiveness was merely part of the overall decrease in reactivity or possibly a more direct result of the specific anatomic lesion. Poirier could not give a specific answer to this, but since the monkeys became more active and alert following apomorphine, it suggested to him that decreased aggressiveness could have been caused by specific interference with responses mediated by dopamine or norepinephrine.

\section{SUMMARY}

(Continued from page 255)

bilateral lesions of the pallidum or of its outflow corresponding, in the main, to the pallidothalamic fibers ending in the ventrolateral thalamus. The latter types of lesion most likely exclude the influence of the monoaminergic, cholinergic and gabaminergic activities normally originating in the striopallidal system and influencing the activity transmitted to other CNS mechanisms. Severe akinesia, however, apparently depends on more profound and generalized disturbances of brain monoamine metabolism with or without the involvement of other ill-defined mechanisms, At any rate the impairment of the brain DA mechanisms (and especially those of the neostriatum) seems to represent a major feature in the production of the Parkinsonian type of akinesia. Further work is needed to establish the relative importance of the loss of catecholaminergic mechanisms other than those of the neostriatum in the production of akinesia. 


\section{RÉSUMÉ}

(Contiued from page 255)

aux) peut aussi s'observer à la suite de l'atteinte bilatérale du pallidum ou de ses efférences principalement constituées des voies pallidothalamiques qui se terminent dans le thalamus ventrolatéral. Ces deux derniers types de lésions excluent vraisemblablement l'influence d'activités dopaminergiques, gabaminergiques et cholinergiques prenant naissance dans le système striopallidal et agissant sur les influx nerveux destinés à d'autres mécanismes du système nerveux central. L'akinésie par ailleurs, semble mettre en cause des perturbations monoaminergiques plus diffuses et plus importantes avec ou sans l'atteinte d'autres mécanismes mal identifiés. Par contre l'inactivation des mécanismes dopaminergiques (surtout au niveau du néostriatum) selon toute évidence constitue le facteur le plus important dans la production de l'akinésie de type parkinsonien. Des études ultérieures sont nécessaires pour déterminer l'importance relative des perturbations des mécanismes catécholaminergiques autres que ceux du néostriatum dans la physiopathologie de l'akinésie.

\section{REFERENCES}

ADAMS, R. D. (1968). The striatonigral degenerations. In: "Handbook of Clinical Neurology", vol. 6, Diseases of the basal ganglia, pp 694-702. Amsterdam: North-Holland Publ. Co.

ADAMS, R. D., BOGAERT, L. VAN, and EECKEN, H. V. VAN DER (1964). Striato-nigral degeneration. Journal of Neuropathology and Experimental Neurology, 23, 584-608.

ANDEN, N.-E., DAHLSTROM, A., FUXE, K. and LARSSON, K. (1965). Further evidence for the presence of nigro-neostriatal dopamine neurons in the rat. American Journal of Anatomy, $116,329-333$.

ANDEN, N.-E., DAHLSTROM, A., FUXE, K. and LARSSON, K. (1966). Functional role of the nigro-neostriatal dopamine neurons. Acta Pharmacologica et Toxicologica, 24, 263-274.

BÉDARD, P. (1974). Etude neuroanatomique, neurochimique et neuropharmacologique de la voie nigrostriée. Thèse, Québec, $127 \mathrm{pp}$

BÉDARD, P., LAROCHELle, L., PARENT, A. and POIRIER, L. J. (1969). The nigro-striatal pathway: a correlative study based on neuroanatomical and neurochemical criteria in the cat and the monkey. Experimental Neurology, 25, 365-377.

BEDARD, P., LAROCHELLE, L., POIRIER, L. J. and SOURKES, T. L. (1970). Reversible effect of L-DOPA on tremor and catatonia induced by $\alpha$-methyl-p-tyrosine. Canadian Journal of Physiology and Parmacology, 48, 82-84.

BEIN, H. J. (1953). Zur pharmacologie des reserpin, eines neuen alkaloids aus rauwolfia serpentina benth. Experientia, 9, 107-110.

BENDA, C. F. and COBB, S. (1942). Pathogenesis of paralysis agitans (Parkinson's Disease). Archives of Neurology and Psychiatry, 48, 154-156.

BERNHEIMER, H., BIRKMAYER, W. und HORNYKIEWICZ, O. (1961). Veirteilung des 5-hydroxytryptamins (Serotonin) im gehirn des menschen und sein verhaltern bei patienten mit parkinson-syndrom. Klinische Wochenschrift, 39 , 1056-1059.

BERNHEIMER, H., BIRKMAYER, W. und HORNYKIEWICZ, O. (1963). Zur biochemie des parkinson-syndroms des menschen. Klinische Wochenschrift, 41, 465-469.

BERNHEIMER, H., BIRKMAYER, W., HORNYKIEWICZ, O., JELLINGER, $K$. and GEITELBERGER, F. (1973). Brain dopamine and the syndromes of Parkinson and Huntington. Journal of the Neurological Sciences, 20, 415-455.

BERNHEIMER, H. und HORNYKIEWICZ, $O$. (1965). Wirkung von phenothiazin-derivaten auf den dopamin-(3-hydroxytyramin-) Stoffwechsel im nucleus caudatus. Archiv. fû̀r experimentalle Pathologie und Pharmakolog ie, 251, 135-136.

BUCY, P. C. and CASE, T. J. (1949). Tremor. Physiologic mechanism and abolition by surgical means. Archives of Neurology and Psychiatry, 41, 721-746.

CARPENTER, M. B. (1956). A study of the red nucleus in the rhesus monkey. Anatomic degeneration and physiologic effects resulting from localized lesions of the red nucleus. Journal of comparative Neurology, 105, 195-249.

CARPENTER, M. B. (1961). Brain stem and infratentorial neuraxis in experimental dyskinesia. Archives of Neurology, 5, 504-524.

CARREA, R. M. E. and METTLER, F. A. (1947). Physiologic consequences following extensive removals of the cerebellar cortex and deep cerebellar nuclei and effect of secondary cerebral ablations in the primate. Journal of comparative Neurology, 87, 169-288.

CONTAMIN, F., ESCOUROLLE, R., NICK, J. et MIGNON, B. (1971). Atrophie pallido-nigroluysienne. Syndrome akinétique avec palilalie, rigidité oppositionnelle et catatonie. Société de neurologie de Paris, 4, 2.

COOPER, I. S. (1969). Involuntary movement disorders. Hoeber Medical Division Harper \& Row, Publishers, New York, Evanston, London.

COOPER, I. S. and BRAVO, G. J. (1958). Implications of a five-year study of 700 basal ganglia operations. Neurology, 8, 701-707.

DAHLSTROM, A. and FUXE, K. (1964). Evidence for the existence of monoamine-containing neurons in the central nervous system. I. Demonstration of monoamines in the cell bodies of brain stem neurons. Acta physiologica scandinavica, 62 (suppl.), 232, 1-55.

DEGKWITZ, R., FROWEIN, R., KULENKAMPFF, C. and MOHS, V. (1960). Uber die Wirkungen des L-DOPA beim menschen und deren beeinflussung durch reserpin, chlorpromazin, iproniazid und vitamin B6. Klinische Wochenschrift, 38, 120-123.

DELAY, J, DENIKER, P., BOURGUIGNON, A et LEMPERIERE, T. (1956). Complications d'allure extrapyramidale au cours des traitements par la chlorpromazine et la réserpine: étude clinique et électromyographique. Encéphale, 45 1093-1098.

DIVRY, P. J., BOBON, J. et COLLARD, J. (1960). Rapport sur l'activité neuropsychopharmacologique du haloperidol (Rol625). Acta neurologicala et psychiatrica Belgica, 60, 7-19.

EHRINGER, H. und HORNYKIEWICZ, O. (1960). Verteilung von Noradrenalin und Dopamin (3-hydroxytyramin) im Gehirn des menschen und ihr verhalten bei erkrankungen des extrapyramidalen systems. Klinische Wochenschrift, 38, 1236-1239.

ERNST, A. M. (1967) Mode of action of apomorphine and dexamphetamine on gnawing compulsion in rats. Psychopharmacologia (Berlin), 10, 361-323.
ESCOUROLLE, R., DE RECONDO, J. et GRAY, F. (1971). Etude anatomo-pathologique des syndromes parkinsoniens. In: Symposium Bel-Air IV, Genève, pp. 173-229, Ed. Masson \& Cie, Paris.

FILION, M., LAROCHELLE, L, and POIRIER, L. J. (1974). Globus pallidus unit activity in a monkey with a Parkinson-like syndrome. Effect of apomorphine. Clinical Research, 22, 854A, (abstract).

GOLDSTEIN, M., ANAGNOSTE, B., BATTISTA, A. F., OWEN, W. S. and NAKATANI, S. (1969a). Studies of amines in the striatum in monkeys with nigral lesions. Journal of Neurochemistry, 16, 645-653.

GOLDSTEIN, M., ANAGNOSTE, B., OWEN, W. S. and BATTISTA, A. F. (1966). The effects of ventromedial tegmental lesions on the biosynthesis of catecholamines in the striatum. Life Sciences, 5, 2171-2176.

GOLDSTEIN, M., BATTISTA, A. F., ANAGNOSTE, B. and NAKATANI, S. (1969b). Tremor production and striatal amines in monkeys. In: "Third Symposium on Parkinson's Disease" pp. 37-40. Ed. F. G. Gillingham, I. M. L. Donaldson. Edinburg and London: E. \& S. Levingstone Ltd.

GUIOT, G. et BRION, S. (1953), Traitement des mouvements anormaux par la coagulation pallidale. Revue neurologique, 89, 578-580.

HARRISON, F. (1940). An attempt to produce sleep by diencephalic stimulation. Journal of Neurophysiology, 3, 156-165.

HASSLER, R. (1938). Zur pathologie der Paralysis agitans und des postenzephalitischen Parkinsonismus. Journal of Psychiatry and Neurology, (Leipzig) 48, 5-6, 387-476.

HASSLER, R. und RIECHERT, T. (1958). Ueber die Sympotomatik und operative Behandlung der extrapyramidalen Bewegunsstörungen. Medizinische Klinik, 53, 19, 817-824.

HELLER, A., HARVEY, J. and MOORE, R. (1962). A demonstration of a fall in brain serotonin following central nervous system lesion in the rat. Biochemical Pharmacology, 11, 859-866.

HOFFMAN, P. (1934). Die physiologischen Eigenschaften der Eigenreflexe. Ergebnisse der Physiologie, Biologischen Chemie und Experimentalen, 36, 15-108.

HORNYKIEWICZ, O. (1963). Die topische Lokalisation und das Verhalten von Noradrenalin und Dopamin (3-hydroxytyramine) in der Substantia nigra des normalen und Parkinsokranken Menschen. Wien klinische Wochenschrift, 75 , 309-312.

HORNYKIEWICZ, O. (1966). Dopamine (3-Hydroxytyramine) and brain function. Pharmacological Review, 18, 925-964.

HORNYKIEWICZ, O. (1971). Neurochemical pathology and pharmacology of brain dopamine and acetylcholine: Rational basis for the current drug treatment of Parkinsonism. In: "Recent advances in Parkinsons' Disease," Contemporäry Neurology Series, pp. 33-65.

KIM, J. S., BAK, I. J., HASSLER, R. and OKADA, Y. (1971). Role of aminobutyric acid (GABA) in the extrapyramidal motor system. 2. Some evidence for the existence of a type of GABA-rich strio-nigral neurons. Experimental Brain Research, 14, 95-104.

KLEMME, R. M. (1940). Surgical treatment of dystonia, paralysis agitans and athetosis. Archives of Neurology and Psychiatry, 44, 4, 926.

KREMER, M., RUSSELL, W. R. and SMYTH, G. E. (1947). A mid-brain syndrome following head injury, Journal of Neurology, Neurosurgery and Psychiatry, 10, 49-60. 
KUO, J. S. and CARPENTER, M. B. (1973). Organization of pallidothalamic projections in the Rhesus Monkey. Journal of comparative Neurology, 151, 201-236.

LANCASTER, G., LAROCHFELE, L., BÉDARD, P., MISSALA, K., SOURKES, T. L. and POIRIER, L. J. (1970). Effect of brain lesions and of harmaline on the dopa decarboxylase activity of striatum of the cat. Journal of neurological Sciences, 1, 265-274.

LAROCHELLE, L., BEDARD, P., BOUCHER, R. and POIRIER, L. J. (1970). The rubro-olivocerebello-rubral loop and postural tremor in the monkey. Journal of neurological Sciences, 11, 53-64.

LAROCHELLE, L., BÉDARD, P., POIRIER, L. J. and SOURKES, T. L. (1971). Correlative neuroanatomical and neuropharmacological study of tremor and catatonia in the monkey. Neuropharmacology, 10, 273-288.

LAROCHELLE, L., PÉCHADRE, J. C. and POIRIER, L. J. (1974). Parkinson's syndrome: An experimental model. Clinical Research, 22, 755A, (abstract).

LLOYD, K. and HORNYKIEWICZ, O. (1970). Parkinson's disease: Activity of L-DOPA decarboxylase in discrete brain regions. Science, 170 , 1212-1213.

McGEER, E. G., FIBIGER, H. C., McGEER, P. L. and BROOKE, $S$. (1973). Temporal changes in amine synthesizing enzymes of rat extrapyramidal structures after hemitransections or 6-hydroxydopamine administration. Brain Research, 52, 289-300.

METTLER. F. A. and WHITTIER, J. R. (1947). The experimental production of abnormal involuntary movements in primates. Transactions of the American Neurological Association, 72, 96-101; 190-192.

MEYERS, R. (1942). The modification of alternating tremors, rigidity and festination by surgery of the basal ganglia. Research Publications of the Association for Research in Nervous and Mental Disorders, 21, 602-665.

NAUTA, W. J. H. and MEHLER, W. R. (1966). Projections of the lentiform nucleus in the monkey. Brain Research, 1, 3-48.

OHYE, C., BOUCHARD, R., LAROCHELLE, L., BEDARD, P., BOUCHER, R., RAPHY, B. and POIRIER, L. J. (1970). Effect of dorsal rhyzotomy on postural tremor in the monkey. Experimental Brain Research, 10, 140-150.

OLIVIER, A., PARENT, A., SIMARD. H. and POIRIER, L. J. (1970). Cholinesterasic striopallidal and striatonigral efferents in the cat and the monkey. Brain Research, 18, 273-282.

PARENT, A., SAINT-JACQUES, C. and POIRIER, L. J. (1969). Effect of interrupting the hypothalamic nervous connections on the norepinephrine and serotonin content of the hypothalamus. Experimental Neurology, 23, 67-75.
PETERSON, E. W., MAGOUN, H. W., MCCULLOCH, W. S. and LINDSLEY, D. B. (1949). Production of postural tremor. Journal of Neurophysiology, 12, 371-384.

POIRIER, L. J. (1960). Experimental and histological study of midbrain dyskinesias. Journal of Neurophysiology, 23, 534-551.

POIRIER, L. J., BÉDARD, P., BOUCHER, R., BOUVIER, G., LAROCHELLE, L., OLIVIER, A. and SINGH, P. (1969a). The origin of different striato- and thalamo-petal neurochemical pathways and their relationship to motor activity. In: "Third Symposium of Parkinson's Disease," pp. 60-66. Ed. F. J. Gillingham and I. M. L. Donaldson, Edinburgh and London: E. \& E. Livingston Ltd.

POIRIER, L. J., BÉDARD, P., LANGELIER, P., LAROCHELLE, L., PARENT, A. et ROBERGE, A. G. (1972). Les circuits neuronaux impliqués dans la phy siopathologie des syndromes parkinsoniens. Revue neurologique, 127, 37-50.

POIRIER. L. J., BOUVIER, G., BÉDARD, P., BOUCHER, R., LAROCHELLE, L., OLIVIER, A. et SINGH, P. (1969b). Essai sur les circuits neuronaux impliqués dans le tremblement postural et l'hypokinésie. Revue neurologique, 120 , 15-40.

POIRIER, L. J., FILION, M., LANGELIER, P. and LAROCHELLE, L. (1975). Brain nervous mechanisms involved in the so-called extrapyramidal motor and psychomotor disturbances. Progress in Neurobiology, (in press).

POIRIER, I. J., LAFLEUR, J., DE LEAN, J. BOUCHER, R., GUIOT, G. and LAROCHELLE, L. (1974). Physiopathology of the cerebellum in the monkey. Part II. Motor disturbances associated with partial and complete destruction of cerebellar structures. Journal of neurological Sciences, 22, 491-509.

POIRIER, L. J., McGEER, E. G., LAROCHELLE, L., McGEER, P. L., BÉDARD, P. and BOUCHER, R. (1969c). The effect of brain stem lesions on tyrosine and tryptophan hydroxylases in various structures of the telencephalon of the cat. Brain Research, 14, 147-155.

POIRIER, L. J., SINGH, P., BOUCHER, R., BOUVIER, G. OLIVIER, A. and LAROCHELLE, P. (1967a). Effect of brain lesions on the concentration of the striatal dopamine and serotonin in the cat. Archives of Neurology, 17, 601-608.

POIRIER, L. J., SINGH, P., SOURKES, T. L. and BOUCHER, R. (1967b). Effect of amine precursors on the concentration of striatal dopamine and serotonin in cats with or without unilateral brain stem lesions. Brain Research, 6, 654-666.

POIRIER. L. J. and SOURKES, T. L. (1965). Influence of the substantia nigra on the catecholamine content of the striatum. Brain, 88, 181-182.

POIRIER, L. J. and SOURKES, T. L. (1972). Experimentally induced Parkinsonism. Research
Publication of the Association for Research in nervous and mental Disorders, 50, 416-433.

POIRIER, L. J., SOURKES, T. L., BOUVIER, G., BOUCHER, R. and CARABIN, S. (1966). Striatal amines, experimental tremor and the effect of harmaline in the monkey. Brain, 89, 37-52.

POLLOCK, L. J. and DAVIS, L. (1930). Muscle tone in Parkinsonian states. Archives of Neurology and Psychiatry, 23, 303-319.

RAJPUT, A. H., KAZI, K. H. and ROZDILSKY, B. (1972). Striatonigral degeneration: response to levodopa therapy. Journal of Neurological Sciences, 16, 331-341

RANSON, S. W. (1939). Somnolence caused by hypothalamic lesions in the monkey. Archives of Neurology and Psychiatry, 41, 1-23.

RANSON, S. W. and INGRAM, W. R. (1932). Catalepsy caused by lesions between the mammillary bodies and III nerve in the cat. American Journal of Physiology, 101, 690-696.

RONDOT, P. et RIBADEAU DUMAS, J. L. (1972). Dopamine et mouvements anormaux. Revue neurologique, $127,99-113$.

SINGH, P., POIRIER, L. J, and BOUCHER, R. (1967). Effect of monoamine oxidase inhibitors on the concentration of dopamine and serotonin in the striatum of the cat with and without unilatera brain stem lesions. Canadian Journal of Physiology and Pharmacology, 45, 897-904.

SOURKES, T. L. and POIRIER, L. J. (1966) Neurochemical bases of tremor and other disorders of movements. Canadian Medical Associa tion Journal, 94, 53-60.

SPECTOR, S., SJOERDSMA, A. and UDENFRIEND, S. (1965). Blockade of endogenous norepinephrine synthesis by a-methyl-tyrosine, an inhibitor of tyrosine hydroxylase. Journal of Pharmacology, 147, 86-95.

SZABO, J. (1962). Topical distribution of the striatal efferents in the monkey. Experimental Neurology, 5, 21-36.

TRÉTIAKOFF, C. (1919). Contribution à l'étude de l'anatomie pathologique du locus niger de Soemmering avec quelques déductions relatives à la pathogénie des troubles du tonus musculaire de la maladie de Parkinson. Thèse, Paris.

UDENFRIEND，S. ZATZMAN-NIRENBERG and NAGATSU, T. (1965). Inhibitors of purified beef adrenal tyrosine hydroxylase. Biochemistry and Pharmacology, 14, 837-845.

VONEIDA, T. (1960). An experimental study of the course and destination of fibers arising in the head of the caudate nucleus in the cat and the monkey. Journal of Comparative Neurology, 115, 75-87.

WARD, A. A. JR., McCULLOCH, W. S. and MAGOUN, H. W. (1948). Production of an alternating tremor at rest in monkeys. Journal of Neurophysiology, 11, 317-330.

WIESENDANGER, M. (1972). Pathophysiology of Muscle Tone. Springer-Verlag: Berlin, Heidelberg: New York. 